\title{
TransDigital
}

\section{A cooperative educational project between architecture and crafts}

\author{
Marco Hemmerling ${ }^{l}$ \\ ${ }^{1}$ Cologne University of Applied Sciences \\ ${ }^{1}$ marco.hemmerling@th-koeln.de
}

Even though the computer acts as an effective interface for the cooperation of various actors involved in the construction, the success of a project depends crucially on the socio-cultural characteristics and disciplinary boundary conditions of the people involved. In addition to the technological challenges of digitisation, different working methods, requirements and objectives often represent an obstacle to the successful cooperation and execution of architectural projects. This is where we as a university are challenged to point out new ways that are geared to the future requirements of our professions and, as it were, integrate individual professional profiles. Against this background, the cooperative education project brought together architecture students and trainees in the carpentry trade in order to help them gain an understanding for their respective differing approaches and for their own expertise at an early stage in training, and thus experience the added value of a cooperative working method. The teaching of digital design and planning methods as well as the use of computer-aided production technologies were the vehicles for networked cooperation and integrative learning.

Keywords: cooperative learning, interdisciplinary collaboration, architecture curriculum, digital design and fabrication

\section{INTRODUCTION}

The progressive digitisation of the development and production processes in architecture has a major influence on job profiles in the planning and building industry. The computer has become indispensable in the design and planning process of architects and specialist planners. The production and assembly of buildings, rooms and objects is also becoming increasingly based on digital technologies. Even though the computer acts as an effective interface for the cooperation of various actors involved in the construction, the success of a project depends crucially on the socio-cultural characteristics and disciplinary boundary conditions of the people involved. In addition to the technological challenges of digitisation, different working methods, requirements and objectives often represent an obstacle to the successful cooperation and execution of architectural projects. This is where we as a university are challenged to point out new ways that are geared to the future re- 
quirements of our professions and, as it were, integrate individual professional profiles. The transfer of information and knowledge between different job profiles as well as interdisciplinary and intercultural cooperation should be strengthened. To this end, new methods of knowledge transfer are needed.

Against this background, the cooperative education project TransDigital brought together architecture students and trainees in the carpentry trade in order to help them gain an understanding for their respective differing approaches and for their own expertise at an early stage in training, and thus experience the added value of a cooperative working method. The teaching of digital design and planning methods as well as the use of computer-aided production technologies were the vehicles for networked cooperation and integrative learning.

But how do architects and carpenters work in the age of digitalisation and what do you need for successful cooperation between the two disciplines? And above all: How can we design a learning environment that enhances the idea of this collaborative approach. Based on these questions, 12 students and 12 trainees developed and implemented the spatial concept RandomizeBox/Co-Working Space working in interdisciplinary teams.

\section{EDUCATIONAL CONCEPT}

\subsection{Didactic approach}

Walter Gropius, looking back at the Bauhaus, described an approach towards the new technologies of the time that provided an important impetus for the didactic concept of the cooperative project: "Our objective was to eliminate the draw-backs of the machine without sacrificing any one of its real advantages. Experiment once more become the center of architecture, and that demands a broad, coordinating mind, not the narrow specialist" .

Trying out, testing, crossing borders, exploring, discovering and "making" is originally associated with the development of architecture. The experiment not only dissolves the boundaries between research, teaching and practice, but also creates a change of perspective from teaching to learning. Hence, the following didactic models support the didactic approach:

- The theory of Design thinking forms the conceptual framework for the desired creative development process and interdisciplinary exchange. It is based on the assumption that problems can be solved better if people from different disciplines work together in an environment that promotes creativity, jointly develop an issue, take people's needs and motivations into account and then develop concepts that are tested several times.

- Research-Based Design describes a researchled development process. The design method is oriented towards the construction of prototypes and includes the exploration of various design concepts as well as the processaccompanying evaluation of the results and successive optimization of the proposed solutions.

- Design-Build projects combine practice and teaching. The realisation of a building, from the conceptual idea, through design and planning to execution, is carried out jointly with students. If one understands the structural implementation as a goal of the creative activity, the examination with the construction and building offers an enormous learning potential.

\subsection{Preparation phase}

TransDigital was developed as an experimental cooperation between the partners, without a concrete reference project which could be built on. Although there was previous knowledge and project experience on both sides that flowed into the educational project, the consistently discipline-spanning orienta- 
Figure 1

Didactic concept and structure of the collaborative project.

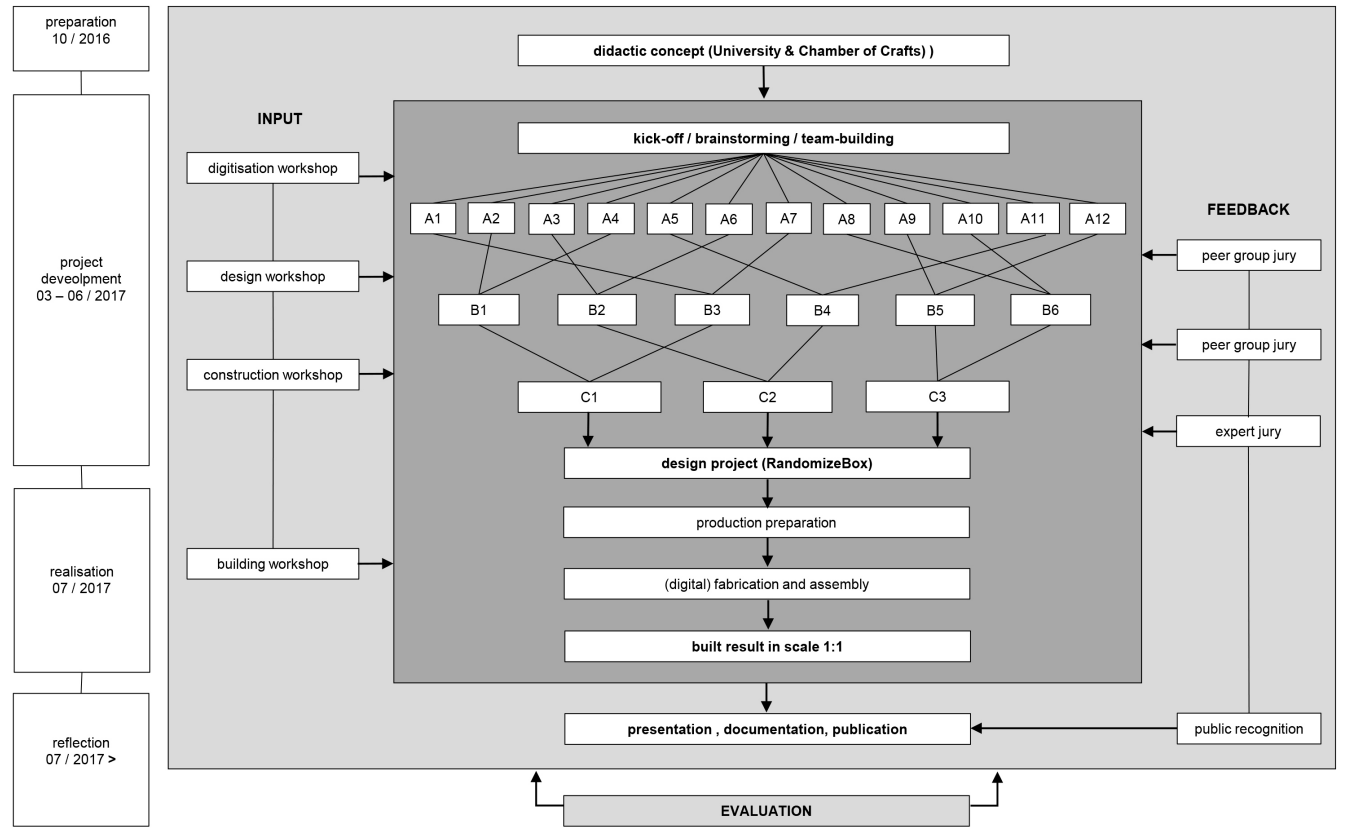

tion represents a new approach, both for trade training and for architectural studies at the university. The teaching and learning format was therefore developed specifically for the different perspectives and requirements of both parties and could serve as a prototype for a new type of training in architecture and trade.

In developing the concept for the cooperative training project, it was essential to create a safe and activating learning arrangement for students and trainees. The change of perspective from teaching to learning was the starting point for the design of a motivating and successful teaching and learning environment for both cooperation partners. The teaching model was deliberately designed as an open-ended bottom-up structure so that participants could actively participate in the development process. In the 2017 summer term, the cooperative and experimental approach was implemented at the Faculty of Architecture in cooperation with the Chamber of Crafts in Cologne as part of the elective Bachelor module "Building with the Computer". The TransDigital diagram serves to illustrate the didactic model and the project progression, which is described in more detail below.

\subsection{Kick-off}

The experimental module started with a kick-off workshop which, after an introduction to the subject, directed the students and trainees into an active and creative role, in which they formulated individual requirements from their areas of knowledge and experience in writing and presented them to the group - according to the "Think-Pair-Share" principle of cooperative learning . As a result, the first focal points emerged, and a common understanding of the project was significantly enhanced right from the start. The event also formed the basis for 
the formation of 12 interdisciplinary teams, which subsequently developed initial ideas for a common workspace for architects and carpenters.

\subsection{Project Development}

A competition structure consisting of three consecutive selection stages (quarter-final, semi-final and final) was defined as a conceptual framework for action. The teams thus developed a large number of innovative approaches at short intervals. Following the credo of Nobel Prize winner Linus C. Pauling: "The best way to have a good idea, is to have a lot of ideas"

The supplementary teaching and learning modules used in the course of the project were integrated into this structure as input and feedback loops. The input topics were incorporated by the lecturers of the university and the trainers of the Chamber of Trades and Crafts (HWK) or also jointly in the form of workshops (digitisation, design, construction, building). Meanwhile the feedback loops consisted of moderated Peer Group juries (students and trainees evaluating the work), in which the presented project ideas were discussed, with proposals made for the next stage of the competition. Individual solutions were selected, and new teams were brought together for the next round. In the course of the competition, the number of teams $(12>6>3)$ was halved and the number of members per team doubled with each competition level. Consequently, project ideas were worked out in greater detail, and discussions and exchanges between the participants were intensified.
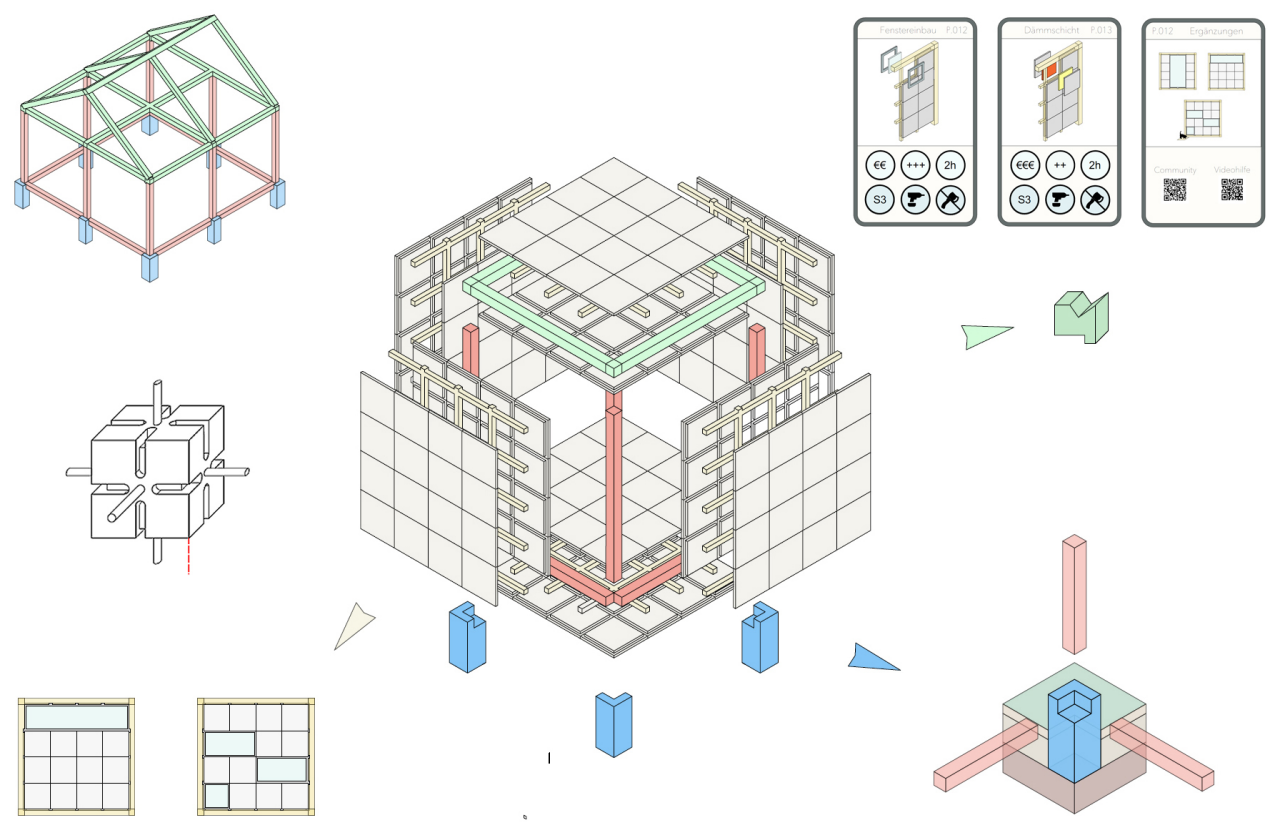

Figure 2

Design concept of the modular prototype "RandomizeBox Co-WorkingSpace". 
The final judging in the final round was carried out by independent experts from both disciplines (university and trade) who were previously unfamiliar with the project. The classification and appreciation of the work "from the outside" led students and trainees to identify even more strongly with the project. At this stage, too, partial aspects of the work were selected and finally merged into the RandomizeBox/Co-Working Space integrative concept.

\subsection{Implementation phase}

In architecture, structural implementation is the goal of the design phase. Or as the German graphic designer Otl Aicher put it: "thinking is the flipside of doing" . In this respect, the examination of the boundary condition of the implementation generates enormous learning potential, which consequently also plays a central role in the TransDigital project. For students in particular, this phase was characterised by a steep learning curve.

In preparation for the structural implementation, the teams were divided into thematic groups, so that development of a central digital model, structure design, development of usage scenarios, identification and ordering of materials, workflow planning as well as assembly and structure strategy, could all be developed in parallel. This method of working required a clear organisational structure, which was set up in the form of work plans with a clear division of tasks. The central data model of the design served as an important decision-making and communication instrument throughout the course of the project. Based on the open source concept, this digital 3D model was accessible to everyone involved in the development process. This OER (Open Educational Resource) was set up on a server of the Faculty of Architecture with access for all participants. The students and apprentices were thus able to be interactively integrated into teaching/learning processes in the sense of research learning using digital technology. With regard to architecture as a design discipline, this approach is based on the principles of Design-based re- search, which use a combination of practice and theory to generate knowledge at the centre of the educational concept.

The wooden components of the RandomizeBox and the furniture of the Co-Working Space were manufactured and then assembled together in a twoweek construction workshop at the Butzweiler Hof training centre. Since many decisions had to be taken during construction-related planning, close coordination of the work processes was necessary. The individual production steps were therefore precisely prepared by the trainers to ensure a smooth process. The self-motivation of the participants and the fact that the teams were already working very well together at this time contributed significantly to the experimental construction being completed in the given time and allowed them to take pleasure in doing so. The result of the cooperation - a flexible, modular timber construction system based on the open source concept - represents an innovative approach to future construction. The design principle is openly available in version 1.0 and can therefore be further developed and adapted to the respective requirements.

\section{CONCLUSION}

One of the main challenges of the project was the organisational coordination between the cooperation partners involved. The different time and administrative requirements (e.g. term structure/examination periods vs. vocational school agenda/requirements of the training companies). This required a high degree of flexibility and commitment from all those involved. Furthermore, it must be noted that the set scope of the project (bottom-up process, multiple judging steps and 1:1 implementation) partly overstretched the one-term formats. In future projects, more time should be allowed for the implementation phase and its preparation. The bottom-up approach also led to a certain overload in some participants, which consisted in the fact that the prerequisites for one's own actions and thinking partly had to be created first. A clear specification of the steps to be carried out and the concrete formulation of 

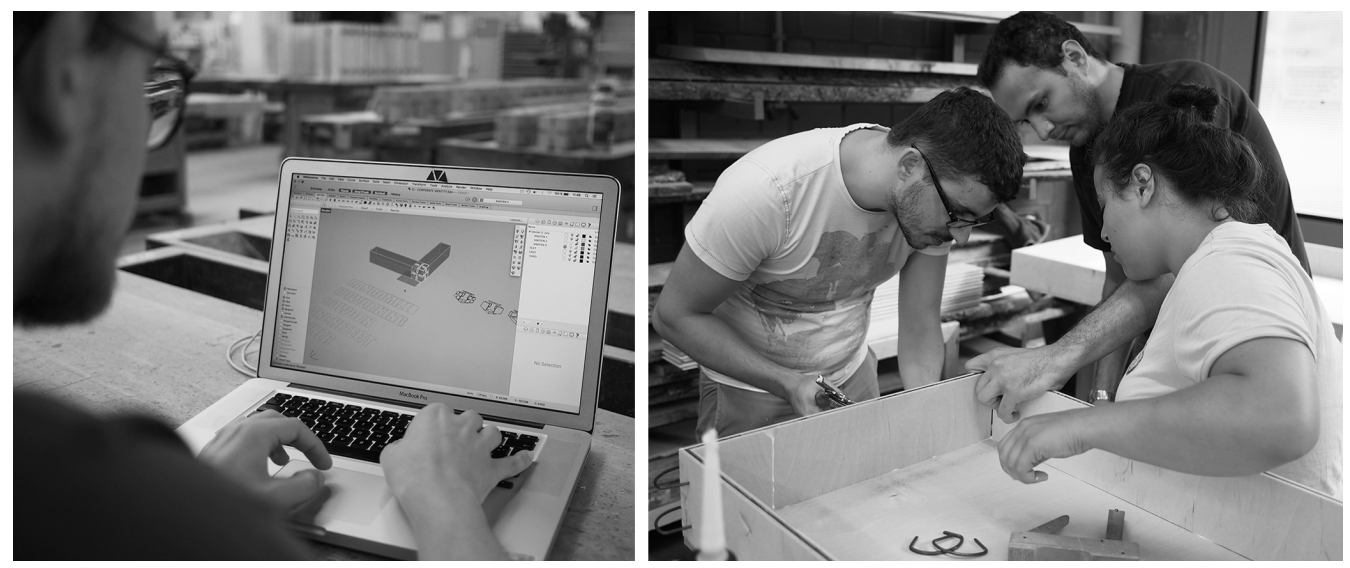

Figure 3

Collaborative

working process

from digital design

to manufacturing.

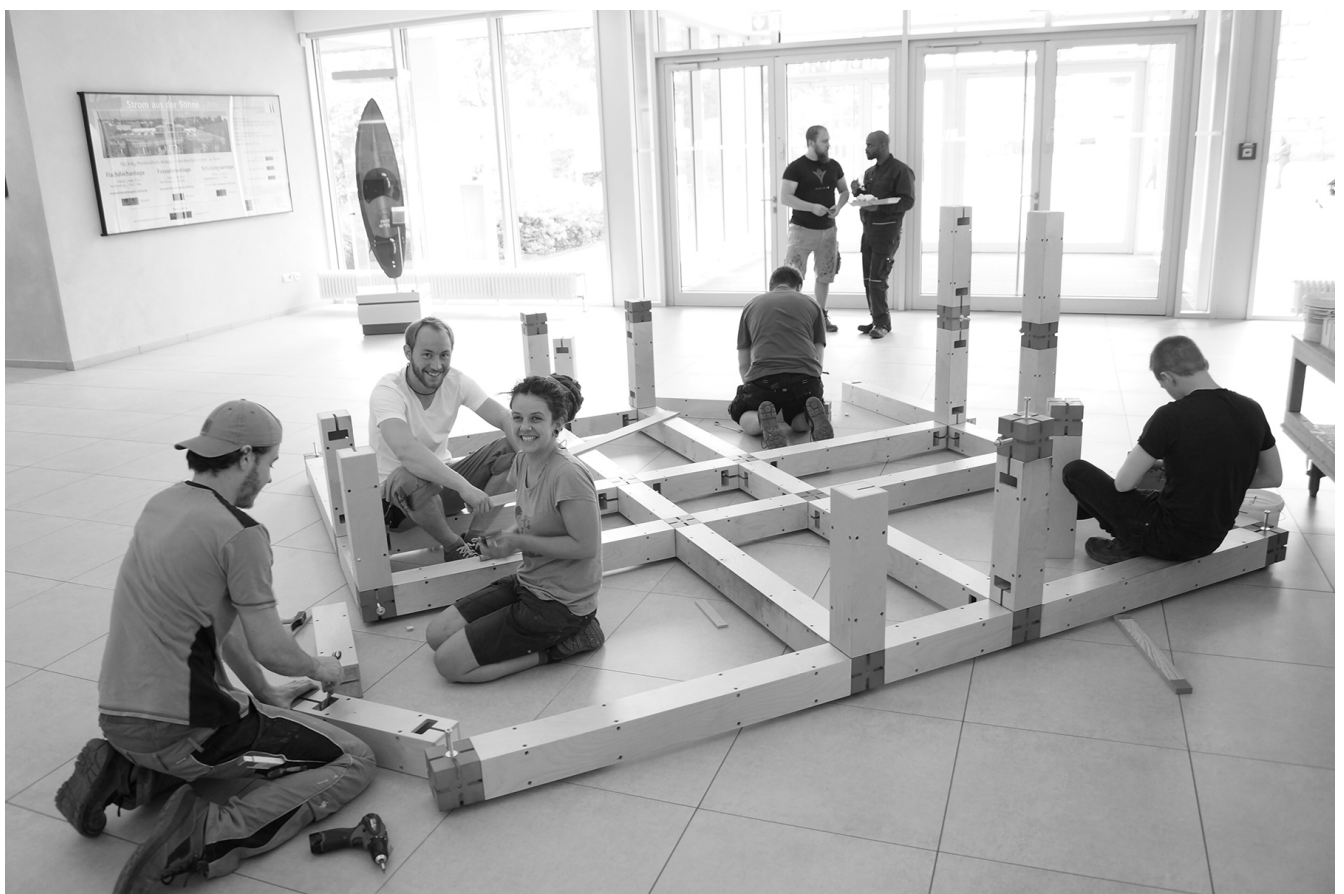

Figure 4

Assembly of the

modular wood

structure 
Figure 5

Digital design model and final structure of the RandomizeBox / Co-Working Space.
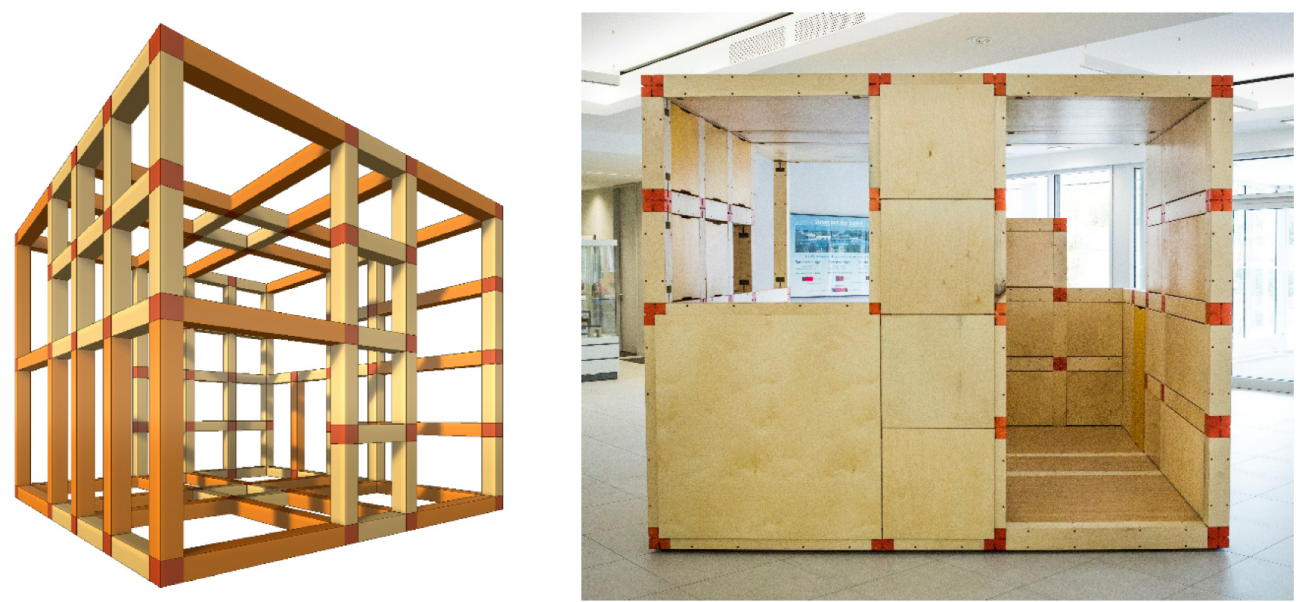

the expected result was deliberately not introduced from outside in the inductive approach but developed step by step within the team in the processes.

Nevertheless, learning success was consistently assessed positively by all participants. This notably applies to the cooperation itself. The intensive exchange of opinions, knowledge and experience as well as the new understanding of the respective own and other disciplines were among the essential findings of the education project. In addition, digitisation was often recognised as an opportunity for improved cooperation and a networked working methodology. Over the course of time TransDigital has developed a valuable momentum of its own, which came from the participants, but also supported and further motivated them. This was made clear above all by the high level of personal responsibility and initiative of students and trainees, after completion of the actual module. One year later, the project remains active.

\section{OUTLOOK}

The successful cooperation will be further developed in a follow-up project during the 2019 summer and winter term. The Building Information Modeling (BIM) planning method forms the basis for an extended cooperative approach that aims at a realization of a new digital laboratory on the university campus, involving additional institutes(civil engineering, project management, energy-optimized construction) and external project members (City of Cologne, industry partners). The aim is the interdisciplinary development and realisation of a timber construction system in self-construction as part of a teaching and research project at the Cologne University of Applied Sciences. The findings from the project are to be transferred into a curriculum and consolidated at the Faculty of Architecture.

\section{REFERENCES}

Aicher, O. 2015, analog und digital: schriften zur philosophie des machens, Verlag Ernst \& Sohn

Anderson, C. 2012, Makers: The New Industrial Revolution, Crown Business, New York

Brown, T. 2008, Design Thinking, Harvard Business Review

Brüning, L. 2012, Professionalisierung durch Schüleraktivierendes Lernen und Kooperatives Lernen, Verlag Hans Huber, Bern

Gropius, W. 1962, Scope of Total Architecture, Collier Books, New York 
Huber, L. 1970, Forschendes Lernen als hochschuldidaktisches Prinzip

Mac Labraihnn, I. 2009, 'From teaching to learning: Challenges for academic staff development', in Schneider, R., Szczyrba, B. and Wildt, J. (eds) 2009, Wandel der Lehr- und Lernkulturen, Bertelsmann, Bielefeld, pp. 44-52

Leinonen, T. 2008 'Software as Hypothesis: ResearchBased Design Methodology', Proceedings of Participatory Design Conference, Indiana, USA

Marinacci, B. 1995, Linus Pauling in His Own Words. Selections from His Writings, Speeches, and Interviews, Touchstone Books, New York

Reeves, T.C., Herrington, J. and Oliver, R. 2005, 'esignbased research: A socially responsible approach to instructional technology research in higher education', Journal of Computing in Higher Education, 16(2), pp. 97-116 